

\title{
Performance of image-based velocimetry (LSPIV) applied to flash-flood discharge measurements in Mediterranean rivers
}

\author{
J. Le Coz, A. Hauet, G. Pierrefeu, Guillaume Dramais, B. Camenen
}

\section{- To cite this version:}

J. Le Coz, A. Hauet, G. Pierrefeu, Guillaume Dramais, B. Camenen. Performance of image-based velocimetry (LSPIV) applied to flash-flood discharge measurements in Mediterranean rivers. Journal of Hydrology, 2010, 394, p. 42 - p. 52. 10.1016/j.jhydrol.2010.05.049 . hal-01058314

\section{HAL Id: hal-01058314 https://hal.science/hal-01058314}

Submitted on 26 Aug 2014

HAL is a multi-disciplinary open access archive for the deposit and dissemination of scientific research documents, whether they are published or not. The documents may come from teaching and research institutions in France or abroad, or from public or private research centers.
L'archive ouverte pluridisciplinaire HAL, est destinée au dépôt et à la diffusion de documents scientifiques de niveau recherche, publiés ou non, émanant des établissements d'enseignement et de recherche français ou étrangers, des laboratoires publics ou privés. 


\title{
Performance of image-based velocimetry (LSPIV) applied to flash-flood discharge measurements in Mediterranean rivers
}

\author{
J. Le Coz ${ }^{* a}$, A. Hauet ${ }^{\mathrm{b}}$, G. Pierrefeu ${ }^{\mathrm{c}}$, G. Dramais ${ }^{\mathrm{a}}$, B. Camenen ${ }^{\mathrm{a}}$ \\ ${ }^{a}$ Cemagref, UR HHLY, \\ 3 bis quai Chauveau, CP 220 F-69336, Lyon Cedex 09, France \\ ${ }^{b}$ EDF-DTG, CHPMC, \\ 62 bis rue Raymond IV, BP 875 F-31685, Toulouse Cedex 09, France \\ ${ }^{c}$ Compagnie Nationale du Rhône, LHM, \\ 4 rue de Châlon-sur-Saône F-69007, Lyon, France
}

\begin{abstract}
Flash-floods that occur in Mediterranean regions result in significant casualties and economic impacts. Remote imagebased techniques such as Large-Scale Particle Image Velocimetry (LSPIV) offer an opportunity to improve the accuracy of flow rate measurements during such events, by measuring the surface flow velocities. During recent floods of the Ardèche river, LSPIV performance tests were conducted at the Sauze-Saint-Martin gauging station without adding tracers. The rating curve is well documented, with gauged discharge ranging from $4.8 \mathrm{~m}^{3} \mathrm{~s}^{-1}$ to $2700 \mathrm{~m}^{3} \mathrm{~s}^{-1}$, i.e., mean velocity from $0.02 \mathrm{~m} \mathrm{~s}^{-1}$ to $2.9 \mathrm{~m} \mathrm{~s}^{-1}$. Mobile LSPIV measurements were carried out using a telescopic mast with a remotely controlled platform equipped with a video camera. Also, LSPIV measurements were performed using the images recorded by a fixed camera. A specific attention was paid to the hydraulic assumptions made for computing the river discharge from the LSPIV surface velocity measurements. Simple solutions for interpolating and extrapolating missing or poor-quality velocity measurements, especially in the image far-field, were applied. Theoretical considerations on the depth-average velocity to surface velocity ratio (or velocity coefficient) variability supported the analysis of velocity profiles established from available gauging datasets, from which a velocity coefficient value of 0.90 (standard deviation 0.05) was derived. For a discharge of $300 \mathrm{~m}^{3} \mathrm{~s}^{-1}$, LSPIV velocities throughout the river crosssection were found to be in good agreement $( \pm 10 \%)$ with concurrent measurements by Doppler profiler (ADCP). For discharges ranging from 300 to $2500 \mathrm{~m}^{3} \mathrm{~s}^{-1}$, LSPIV discharges usually were in acceptable agreement $(<20 \%)$ with the rating curve. Detrimental image conditions or flow unsteadiness during the image sampling period led to larger deviations ranging $30-80 \%$. The compared performances of the fixed and mobile LSPIV systems evidenced that for LSPIV stations, sampling images in isolated series (or bursts) is a better strategy than in pairs evenly distributed in time.
\end{abstract}

Key words: flash-flood, hydrometry, discharge measurement, image analysis, LSPIV

\section{Introduction}

Flash-floods that occur in Mediterranean regions [8] result in significant casualties and economic impacts. Recently, the Gard river flood of 8-9 September, 2002 killed 24 people and damages were evaluated to 1.2 billion euros [4]. The understanding of flood generation and propagation processes requires reliable streamflow estimates throughout the river network, in real time. Flood warning systems are sometimes based on discharge values whose forecast may be conditioned with real-time measurements for a better evaluation of the hydraulic risk.

The most common method for monitoring discharges consists of measuring the water level and establishing a stage-discharge relationship (so-called rating curve, e.g., 22, 23) fitted from a set of direct discharge measurements

\footnotetext{
${ }^{*}$ Corresponding author. Tel: +33 472208786; fax: +33478477875 .

Email addresses: jerome.lecoz@cemagref.fr (J. Le Coz), alexandre.hauet@edf.fr (A. Hauet), g.pierrefeu@cnr.tm.fr (G. Pierrefeu), guillaume.dramais@cemagref.fr (G. Dramais), benoit.camenen@cemagref.fr (B. Camenen) 
(so-called gaugings). The establishment and update of rating curves require the gauging of the whole range of discharge values, including extreme flows. Unfortunately, due to the lack of gaugings during floods, the rating curves empirically established at existing gauging stations often must be extrapolated to high flow rates. The accuracy of the extrapolation can be improved by a hydraulic analysis including collection of post-event data and numerical simulation [15]. However, the errors on extrapolated discharges remain large, resulting in wide credibility intervals associated with flood quantile estimates [15]. Flood discharge measurements constitute the most important data for improving the rating curves and for addressing this hydrological issue.

Gauging methods conventionally used are the velocity-area method (e.g., currentmeters deployed from wading rod, boat, or cableway), Doppler profilers, floats, and chemical tracer dilution. A number of problems make such methods highly difficult or impossible to apply to flash floods. The navigation or even the access to the river shore or the bridges are difficult and often dangerous, due to overbank flooding, high velocities and drifts of varied nature. The short time (a few hours) between the rain event and the peak of flash-floods is a heavy logistic problem for the efficient deployment of hydrometry staffs.

Emerging remote flow monitoring systems, especially those based on radar Bragg diffraction [2] or on image analysis like Large Scale Particle Image Velocimetry (LSPIV, 5, 3, 9, 19) offer promising potential for improving the quality of flash-flood discharge measurements. These remote techniques provide surface velocity measurements which require a known cross-section geometry and some hydraulic assumptions to compute the discharge. One of the key parameters for discharge calculation is the depth-average velocity to surface velocity ratio (or velocity coefficient), whose value and variability should be determined carefully as it induces a multiplicative, systematic discharge error [19]. This parameter may show some variability according to the site and flow conditions.

Remote stream gauging techniques such as LSPIV are valuable new hydrometric tools for gauged sites as well as ungauged sites. At a gauging station with a rating curve, the LSPIV technique provides flood discharge measurements on a broader range than conventional techniques. Subsequently, uncertainties of the extrapolated part of the rating curve can be reduced. Flow measurements available at a gauged site should be used to calibrate and validate the hydraulic assumptions which are made to compute discharge from surface velocity measurements. At a non-gauged site, i.e. without a rating curve nor hydraulic data, realistic hydraulic assumptions can be established from the site characteristics to provide new discharge data with reasonable uncertainty.

The application of the LSPIV technique to flash-floods still have to mature to provide reliable flood discharges. A number of error sources were identified [19], but experimental tests are missing for assessing their relative contributions to the uncertainty associated to LSPIV discharge measurements in high-flow conditions. Jodeau et al. [12] presented a case study with a mobile LSPIV system and high flow conditions during a dam-flushing operation in a mountain river. Due to high suspended-solid concentrations, the artificial seeding of the flow with cornstarch tracers was required to achieve a correct LSPIV analysis. Hauet et al. [10] presented a numerical simulator designed to conduct sensitivity studies on the sources of errors of the LSPIV technique, for varying conditions of measurement. This is a most useful direction of work for assessing the uncertainties associated with the LSPIV discharge measurements. However, the assumptions and results of such a simulator must be validated using comprehensive experimental studies in the laboratory or in the field. Some discharge-discharge comparisons were performed by Creutin et al. [3], Hauet et al. [9], Kim et al. [13], but velocity-velocity comparisons are scarce in the literature: Jodeau et al. [12] compared LSPIV velocities with velocities simulated using a 2D numerical model, not with measured velocities.

This paper reports and analyzes comprehensive performance tests for assessing and improving the quality of the promising LSPIV technique applied to the measurement of peak discharges of Mediterranean flash-floods. The tests were conducted during recent flood events at the outlet of the Ardèche river, at the Sauze-St Martin gauging station managed by the Compagnie Nationale du Rhône (CNR). The accuracy of discharges provided by a fixed LSPIV system [9] and a mobile LSPIV system [13, 12] deployed on the same study site was investigated, as well as the accuracy of the surface velocities provided by the mobile LSPIV system. LSPIV velocity and discharge measurements were compared with accurate reference data (concurrent ADCP measurements, well-documented rating curve). From a practical point of view, the study proposes advances on major sources of errors in LSPIV discharge measurements: image sampling strategies, interpolation and extrapolation of missing velocities, determination of the velocity coefficient value and variability. 


\section{Methods}

\subsection{Theoretical overview of the LSPIV technique}

The principles of the LSPIV technique [5] used in this study are summarized in this section. For a more in-depth review of the principles of LSPIV and its application to riverine environments, the reader may refer to Muste et al. [19] for instance.

\subsubsection{Computation of surface velocities}

As a first step of the LSPIV procedure, images of the river surface sampled with a camera or from an existing movie are orthorectified, i.e., perspective distorsion effects are corrected and pixels are georeferenced. This geometrical correction of the pictures is achieved through a 3D plan-to-plan perspective projection [12]. The 11 parameters of the projection are calibrated from a set of Ground Reference Points (GRP) whose coordinates were measured both in the $2 \mathrm{D}$ image space and the $3 \mathrm{D}$ real space. In orthorectified images, each pixel is georeferenced and corresponds to a constant metric size.

Then, the computation of flow surface velocities is achieved using a classical cross-correlation algorithm [5] applied to each pair of orthorectified images, separated by a given time interval, $\Delta t$. Image patterns associated with tracers naturally present at the free-surface of the flow such as boils, surface ripples, vegetal debris, may be traced, like in the present study. Artificial tracers, such as cornstarch chips for instance [12], may also be injected in the flow to improve the performance of the image analysis. The most likely displacement of the visible tracers is determined as the maximum cross-correlation coefficient computed between two ensembles of gray-scale pixels (interrogation areas, IA, see Fig. 1). For each IA centred on a point $a_{i, j}$ in the first image, the cross-correlation coefficients with the same IA centred at points $b_{i, j}$ in the second image are computed. The points $b_{i, j}$ around each point $a_{i, j}$ are chosen within a search area (SA). The IA should be small enough to preserve the scale of interest in the flow and large enough to include recognizable tracer patterns within it. The dimensions of the SA should be large enough to cover the tracer displacements from $a_{i, j}$ in each direction, and small enough to reduce computational costs.

The process is iteratively conducted for the whole image in a computational grid defined by the positions of the points $a_{i, j}$. Velocity vectors are derived using displacement values divided by $\Delta t$. LSPIV analysis conducted on a set of image pairs yields the instantaneous and time-averaged 2D surface velocity fields. As they are the products of a statistical procedure, computed velocity vectors may be erroneous. Post-processing routines for filtering out erroneous velocities may be based on velocity magnitude/direction thresholds, correlation coefficients, or flow continuity analysis.

\subsubsection{Computation of discharge}

The discharge across the section is computed according to the classical velocity-area method. From a timeaveraged LSPIV surface velocity field, velocities are interpolated at the nodes of a gauging profile across the stream along which the bathymetry is known. In areas where LSPIV failed to measure accurate velocities, typically in the image far-field or outside of the image view, velocities must be extrapolated. Details about the interpolation and extrapolation methods used in this study are given Section 2.4.1.

Then, the LSPIV surface velocities along the gauging profile have to be converted into depth-averaged velocities. A simple and convenient method is the multiplication by a constant velocity coefficient, $\alpha$, defined as the depthaverage velocity to surface velocity ratio. The LSPIV method is applicable at non-gauged sites if an a priori choice of the velocity coefficient value is made. A default value of $\alpha=0.85$ is commonly chosen for river flow studies $[22,3,2,9,13,19]$, assuming a logarithmic vertical velocity distribution and typical bed roughness.

However, the values of $\alpha$ are site-specific and may show significant variability across the river section and over the range of hydraulic conditions. Errors made on $\alpha$ multiplicatively deteriorate the depth-average velocity estimates, hence the LSPIV discharge estimates. For a given experimental site, it is therefore important to establish this value from measurements of the complete flow structure, and to assess the variations of this value. Theoretical considerations on this critical issue, as well as experimental results are provided Section 2.4.2 and Section 2.4.3, respectively. If some vertical velocity profiles are measured, the uncertainty in the velocity coefficient value, hence in the discharge value, can be reduced. 


\subsection{Case Study}

\subsubsection{Experimental site}

At Sauze-St Martin, the lower Ardèche river flows in a straight main channel (Fig. 2), downstream of a long area of narrow gorges. The river morphology shows marked riffle-pool sequences with a mean slope of $0.3 \%$, and Manning coefficients calibrated in a 1D hydraulic model were roughly equal to $0.03 \mathrm{~m}^{-1 / 3} \mathrm{~s}$ [14]. In the reach by the gauging station, the bottom of the main channel is made of inerodible limestone bedrock, with no significant gravel deposits. Therefore, the river morphology is very stable over the years. The cross-sectional profile used for further discharge computations is presented in Fig. 3.

The corresponding catchment area is $2240 \mathrm{~km}^{2}$, and the mean annual discharge is $63 \mathrm{~m}^{3} \mathrm{~s}^{-1}$. The peak discharge values for return periods 2, 5, and 10 years are $Q_{2 y r}=1830 \mathrm{~m}^{3} \mathrm{~s}^{-1}, Q_{5 y r}=2770 \mathrm{~m}^{3} \mathrm{~s}^{-1}, Q_{10 y r}=3390 \mathrm{~m}^{3} \mathrm{~s}^{-1}$, respectively [11]. Like other tributaries of the lower Rhône, the Ardèche river may be affected by flash-floods induced by heavy Mediterranean convective rain events occurring mainly from September to December.

\subsubsection{Rating curve and available gauging data}

Point measurements of the flow rate at Sauze-St Martin gauging station are conducted by CNR either using leaded mechanical currentmeters deployed from a cableway, or using Doppler profiler (ADCP) deployed from mobile boat. Even if some of the oldest currentmeter gauging measurements are not taken into account in the establishment of the currently valid rating curve, they could be used in the analysis of the local flow structure, because they were conducted from the cableway cross-section, collocated with the LSPIV cross-section. Reciprocally, ADCP gauging measurements, especially those corresponding to the highest gauged discharges, were discarded from the velocity coefficient analysis, because for technical reasons they were conducted in cross-sections located downstream of the gauging stations, where the discharge is the same, but not necessarily the flow structure.

The operational rating curve currently used by CNR at Sauze-St Martin is well documented, based on 39 conventional gaugings performed from December, 2003 to February, 2009 (Fig.11, crosses and solid line). The set of valid gaugings covers a broad range of water levels and flow rates: $45.7-52.7 \mathrm{~m}$ above sea level (reference elevation system: NGF IGN69), and $4.8-2700 \mathrm{~m}^{3} \mathrm{~s}^{-1}$, respectively. The corresponding bulk velocities range from $0.02 \mathrm{~m} \mathrm{~s}^{-1}$ to $2.9 \mathrm{~m} \mathrm{~s}^{-1}$. The mean deviation of gauged discharges to the fitted rating curve is $-3 \%$, with no deviations larger than $8 \%$ for discharges larger than $60 \mathrm{~m}^{3} \mathrm{~s}^{-1}$. The uncertainty associated with rated discharges was estimated to be roughly $10 \%$ [20]. Therefore, discharge values provided by the rating curve and the water levels measured by a reliable pneumatic pressure gauge were considered as the reference discharge values for evaluating the concurrent LSPIV discharges. The water levels used in the LSPIV image orthorectification and discharge computation were those measured by the pressure gauge.

\subsection{Experimental set-ups}

\subsubsection{Mobile LSPIV system}

The mobile LSPIV system [13,12] is useful for preliminary tests or flood-triggered measurements at gauging stations deprived of or not yet equipped with a fixed LSPIV system. A commercially available digital videocamera (Canon MV750i) was set on a mobile lightweight telescopic mast, the height of which can be set from 2 to $10 \mathrm{~m}$ (Fig. 4d). The camera was remotely controlled from the ground in order to set the camera on and to adjust view angles. The movies were directly saved on a laptop. The movie format was mini-DV at a rate of 25 frames per second and image resolution was $720 \times 576$ pixels. The movie was sampled at a rate of five images per second $(\Delta t=200 \mathrm{~ms})$, to yield pattern displacements ranging from 10 to 20 pixels, approximately. The resulting instantaneous velocity fields were averaged over 2 minutes of movie, i.e. 600 image pairs. Usual guidelines for the configuration of the LSPIV image processing were followed in this study. We used similar pixel resolution $(0.05 \mathrm{~m} / \mathrm{pixel})$ and IA size $(64 \times 64$ pixels, i.e. $3.20 \mathrm{~m})$ as used by Hauet et al. [9] for their similar application case. The SA dimensions were not restrictive, and relevant for all encountered discharge conditions: 50 pixels $(12.5 \mathrm{~m} / \mathrm{s}), 4$ pixels $(0.2 \mathrm{~m} / \mathrm{s})$, and 10 pixels $(2.5 \mathrm{~m} / \mathrm{s})$ in the downstream, upstream, and spanwise directions, respectively.

\subsubsection{Fixed LSPIV station}

In June, 2008, the Sauze-St Martin gauging station was equipped with a video camera Axis 211M coupled to an industrial PC with external and autonomous power supply (Fig. 4a-b). The time interval between images in a pair was 
set to $\Delta t=200 \mathrm{~ms}$. The same LSPIV parameters were used as for the mobile tests. It was decided to sample no more than 1 pair of images in each $2 \mathrm{~min}$ in order to limitate the size of the data stored in the PC memory. For computing discharge, the velocity fields were averaged over $24 \mathrm{~min}$, i.e., from 12 image pairs. This a priori choice was thought to be a reasonable compromise with a sufficient number of averaged velocity fields over a period of time short enough with respect to hydraulic variations.

The resolution was $800 \times 600$ pixels. Several unexpected problems affected this installation. The focus drifted progressively, so that some images appeared fuzzy. The time interval between the two images in a pair was suspected not to be as accurate as when a mini-DV is sampled. Due to the limited resolution and the a priori chosen view angle, the far-field of the flow was either recorded with poor image quality, or cut due to the water level rise. As the real-time operation of the system was not effective during the 2008 floods, image pairs saved on the PC were post-processed for conducting the tests reported hereafter.

\subsubsection{Topography measurements}

For each mobile tests, and once at the installation of the fixed system, 10 Ground Reference Points (GRP) were positioned along both sides of the river in the image using white $40 \mathrm{~cm} \times 40 \mathrm{~cm}$ square targets (Fig. $4 \mathrm{c}$ ). The GRP were positioned using either a total station (Leica TC305), or a differential GPS (Leica GPS1230 RTK). The cross-sectional profile was established by combining topography measurements with the bathymetry provided by a Teledyne RDI RioGrande ADCP 1.2 MHz. All the position/elevation measurements, including the staff gauge and the pneumatic pressure gauge of the gauging station, were reported in the same coordinate system.

\subsubsection{Hydraulic conditions during test campaigns}

LSPIV discharge validation tests were conducted during three flood events (Fig. 5), in November, 2007 (mobile system, peak discharge $900 \mathrm{~m}^{3} \mathrm{~s}^{-1}$ ), in October, 2008 (fixed system, peak discharge $2500 \mathrm{~m}^{3} \mathrm{~s}^{-1}$ ), in November, 2008 (fixed system, peak discharge $2400 \mathrm{~m}^{3} \mathrm{~s}^{-1}$ ). Image series were acquired for discharges ranging from 300 to $2500 \mathrm{~m}^{3} \mathrm{~s}^{-1}$, i.e., for mean velocities ranging from $1.0 \mathrm{~m} \mathrm{~s}^{-1}$ to $2.9 \mathrm{~m} \mathrm{~s}^{-1}$. In the vicinity of flood peaks, flow conditions were significantly unsteady. The worth case is the 2008/10/22 image series for which the water level dropped at a mean rate of $-0.42 \mathrm{~m} / \mathrm{h}$. The corresponding discharge drop was evaluated to be $-240 \mathrm{~m}^{3} / \mathrm{s}$ per hour, i.e., $-14 \%$ of the mean discharge.

During mobile LSPIV tests conducted on November 11, 2007 around 14:30, for a discharge equal to $330 \mathrm{~m}^{3} \mathrm{~s}^{-1}$, collocated ADCP measurements were simultaneously acquired using a Teledyne RDI RioGrande $600 \mathrm{kHz}$.

During all fixed and mobile LSPIV tests, no artificial tracers were injected. The LSPIV analysis was applied to flow tracers naturally visible at the free surface, mainly ripples and small woody debris.

\subsection{Data processing for computation of discharge}

\subsubsection{Interpolation and extrapolation of velocities along the gauging transect}

The tools and algorithms used for image orthorectification and cross-correlation velocity computation were initially developped by Hauet et al. [9] on the basis of the seminal works by Fujita et al. [5]. However, the computation of discharge, including interpolation and extrapolation of the missing velocities was modified for this study to match better hydrometric requirements. The total discharge across the section is computed according to the classical velocity-area method following a mid-section integration procedure for normal velocities.

The bathymetry profile of the gauging transect used in this study is shown in Fig. 3. The space step between each node of the bathymetry profile is $5 \mathrm{~m}$, approximately. For a given water level, edge nodes with zero water depth and zero velocity are added at the intersection of the free-surface line with the bathymetry profile. At a node surrounded by LSPIV time-averaged velocities, the 'gauged' velocity was computed as the inverse-distance-weighted mean of the 3 nearest LSPIV velocities found within a search radius of $5 \mathrm{~m}$ around the node.

Missing velocities along the wetted width of the cross-sectional profile were interpolated or extrapolated using the method introduced by Fulford and Sauer [7]. From tests on field data with uniform velocity distributions, Fulford and Sauer [7] based their method on the simple assumption that the local Froude number, $V / \sqrt{g h}$, with $V$ local velocity, $h$ local water depth, $g$ gravity acceleration, is constant or varies linearly throughout a river cross-section. Consequently, 
a missing velocity $V_{i}$ at a node $i$ surrounded by nodes 1 and 2 where velocities $V_{1}$ and $V_{2}$ are known may be estimated by:

$$
V_{i}=\frac{a}{L} V_{2} \sqrt{\frac{h_{i}}{h_{2}}}+\frac{L-a}{L} V_{1} \sqrt{\frac{h_{i}}{h_{1}}}
$$

with $L$ the distance between nodes 1 and 2, $a$ the distance between nodes 1 and $i, h_{1}, h_{2}, h_{i}$, the local water depths at nodes $1,2, i$.

Similarly, a missing velocity $V_{j}$ at a node $j$ located between the bank and a node 3 where velocity $V_{3}$ and water depth $h_{3}$ are known may be estimated by:

$$
V_{j}=V_{3} \sqrt{\frac{h_{j}}{h_{3}}}
$$

Such an extrapolation method was particularly useful for documenting far-field or out-of-view areas where velocities were not measurable by LSPIV, or so poorly that it was preferred to discard them (see Section 3.1.2).

\subsubsection{Theoretical considerations on the velocity coefficient variability}

As explained in Section 2.1.2, the conversion of LSPIV surface velocities into depth-averaged velocities is a critical issue for discharge computation. In this study, a constant multiplicative velocity coefficient, $\alpha$, is used to achieve this conversion. Simple theoretical considerations presented hereafter constitute the framework of the experimental method proposed for determining the site-specific value and variability of $\alpha$ in Section 2.4.3.

From the expression of the logarithmic velocity profile induced by the law of the wall with flow depth $h$ and roughness length $z_{0}$, the theoretical value of $\alpha$ is:

$$
\alpha_{\log }=\frac{h}{h-z_{0}}-\left[\ln \frac{h}{z_{0}}\right]^{-1}
$$

Note that if $z_{0}<<h$ is assumed, a simpler formula is obtained [25]. In some cases, this assumption may not be valid. For instance, Smart [24] provided evidence of natural rough turbulent flows that acceptably followed a logarithmic profile over the whole flow depth, with $h / z_{0}$ ranging from 3 to $10^{3}$. The exact formulation (Eq. 3 ) is used to compute the variation of $\alpha_{\log }$ with $h / z_{0}$ (Fig. 6, solid line). For typical values of $h / z_{0}$ in natural streams $\left(10^{2}-10^{4}\right), \alpha_{\log }$ ranges $0.79-0.89$, with a central value close to 0.85 for $h / z_{0}=10^{3}$.

However, vertical velocity profiles in open-channel flows do not always follow the log distribution up to the freesurface. From flume experiments on uniform smooth flows, Cardoso et al. [1] typically observed that the law of the wall describes accurately the flow in the inner region $(z / h<0.2)$ of the boundary layer and also in the outer region, at least for $0.2<z / h<0.7$, where the wake effects are usually weak. We note $\beta$ the maximum relative elevation of the flow below which a log velocity profile is observed. In large rivers with uniform flow distribution, $\beta \sim 0.7$ and roughly constant velocities for $z / h>0.7$ are often observed. Typically, Le Coz et al. [17] analyzed 18 ADCP gauging campaigns conducted across a 10 m-deep, 100 m-wide section of the Saône river at Lyon-St-Georges, France, for a broad range of mean velocities $\left(0.17-2.3 \mathrm{~m} \mathrm{~s}^{-1}\right)$. The mean velocity profile followed such a log-constant distribution, with $\beta=0.65$ [17] and $\alpha=0.91$ with standard deviation $\sigma=0.04$ [16].

Assuming that a velocity profile is logarithmic below a relative elevation $\beta$, and constant above $\beta$, the theoretical value of $\alpha$ is:

$$
\alpha_{\log +c s t}=\frac{h}{h-z_{0}}-\frac{\beta h-z_{0}}{h-z_{0}}\left[\ln \frac{\beta h}{z_{0}}\right]^{-1}
$$

Fig. 6 shows that for typical values of relative roughness $\left(h / z_{0}=10^{2}-10^{4}\right)$ the theoretical value of $\alpha$ may vary by 0.05 or 0.10 according to the assumed vertical velocity distribution $(\beta=1,0.7,0.6)$. Reciprocally, a given value of $\alpha$ may correspond to different values of $h / z_{0}$ according to the value of $\beta$. For instance, assuming $\beta=1,0.7$, or 0.6 , the experimental value of $\alpha=0.91$ for the Saône river at Lyon-St-Georges could be obtained for $h / z_{0}$ values ranging over two decades. However, the physical meaning of $z_{0}$ is not the same, because it results from the fit of a log-constant profile over the whole flow depth, not from the fit of a $\log$ profile below relative elevation $\beta$. Only the $z_{0}$ estimates established with a log fit over the whole or a lower part of the flow depth may be related to the physical bed roughness. 


\subsubsection{Experimental determination of the velocity coefficient value}

In order to assess the variability of the velocity coefficient, $\alpha$, throughout the experimental cross-section, the flow structure measured by ADCP during the mobile LSPIV tests was examined. Fig. 7 shows the ADCP non-dimensional vertical velocity profiles: elevation and velocity are normalized by the local water depth and depth-averaged velocity, respectively. On average, the vertical velocity distribution follows a log-constant profile with $\beta=0.6$. The constant dimensionless velocity value near the free-surface is 1.11 , which means a mean velocity coefficient of $\alpha=0.90$. The experimental standard deviation computed with data from the constant part of the profile $(z / h>\beta)$ is 0.04 , which is of the same order of magnitude as the uncertainty associated with the ADCP velocity measurements. This low value suggests that the dispersion of $\alpha$ throughout the cross-section is negligible, at least for $Q \approx 300 \mathrm{~m}^{3} \mathrm{~s}^{-1}$.

The variability of $\alpha$ with the discharge conditions was also investigated through the analysis of 29 current-meter gaugings conducted from the cableway at Sauze-Saint Martin, covering a discharge range of $30-1600 \mathrm{~m}^{3} \mathrm{~s}^{-1}$, i.e., a mean velocity range of $0.12-2.6 \mathrm{~m} \mathrm{~s}^{-1}$. Cross-sectional velocity coefficients $Q / Q_{2}$ were computed as the ratio of $Q$, the gauged discharge, to $Q_{2}$, the discharge computed with near-surface velocities $(20 \mathrm{~cm})$ instead of depth-averaged velocities (Fig. 8). If the velocity coefficient $\alpha$ is assumed to be homogeneous throughout the cross-section, it equals the cross-sectional velocity coefficient $Q / Q_{2}$. For $Q<300 \mathrm{~m}^{3} \mathrm{~s}^{-1}$, the observed values of $Q / Q_{2}$ are significantly scattered and range from 0.80 to 0.95 . For $Q>300 \mathrm{~m}^{3} \mathrm{~s}^{-1}$, the values of $Q / Q_{2}$ seem less scattered, but data are far too sparse to firmly conclude that $Q / Q_{2}$ converges towards a constant value for high discharges. The mean value of $Q / Q_{2}$ (0.89) is consistent with the mean value of $\alpha$ derived from the ADCP data (0.90). Even if the experimental standard deviation is as low as 0.05 , extreme values of the velocity coefficient would induce discharge errors up to $10 \%$.

As a conclusion of this analysis of the flow structure, the same velocity coefficient value of 0.90 (estimated standard deviation $\sigma=0.05$ ) was used for all LSPIV discharges.

\section{Results and discussion}

\subsection{Results of the LSPIV performance tests}

\subsubsection{LSPIV velocity measurements}

Fig. 9 shows a typical view of the surface velocity measured by LSPIV during the mobile tests conducted on November 11, 2007. The density of the computational grid allowed an extraction of the LSPIV velocities within a few meters of the line of the ADCP transects that were conducted simultaneously. Surface LSPIV velocities reported in Fig. 10 were corrected by the velocity coefficient, $\alpha=0.90$, to be compared with the concurrent ADCP depth-averaged velocities. The overall agreement between both techniques was less than $10 \%$ throughout the cross-section. Larger deviations visible at distances 0 and $50 \mathrm{~m}$ from left side may be explained by differences or errors in spatial sampling. Such a good agreement indicates that the velocities computed by LSPIV are correct, at least for the conditions of the mobile LSPIV test $\left(Q \approx 300 \mathrm{~m}^{3} \mathrm{~s}^{-1}\right)$. Other velocity validation tests for other discharge conditions and also for the fixed LSPIV system would be useful to confirm the robustness of the method.

\subsubsection{LSPIV discharge measurements}

The results of the LSPIV discharge validation tests are summarized in Tab. 1, Tab. 2, and Fig. 11. Results for mobile LSPIV tests (Tab. 1, Fig. 11, squares) showed acceptable deviations from the rating curve: all deviations $<10 \%$, average $+3.2 \%$, standard deviation $5 \%$.

Results for fixed LSPIV tests (Tab. 2) were more contrasted: out of 12 image sequences corresponding to different environmental conditions, 6 showed deviations $>20 \%$, average deviation was $-3.8 \%$, and standard deviation $30 \%$.

Fig. 12 shows the velocity fields computed by the fixed LSPIV system from image sequences with contrasted image conditions and for decreasing river discharge values. Flood image sequences yielded well-organised velocity fields around the gauging transect line (Fig. 12ab). Note that the orthorectified image shrinks when the water level is higher, due to the perspective effect. Accordingly, the range of the image field is reduced, and velocities need to be extrapolated further. Computed discharges deviated acceptably from the rating curve outputs: $-10 \%$ and $-17 \%$, respectively for image sequences (a) and (b).

Image sequences for intermediate discharge (Fig. 12c) and for usual low flow conditions (Fig. 12d) yielded more dispersed velocity fields, with highly perturbated, and obviously irrelevant, vectors in the near field and the far field 
of the image. There should be a lower velocity limit for surface ripples to follow the surface flow, when the diffusion effects of boils and other free-surface perturbations dominate the advection. Near-field errors seem to be caused mainly by solar reflections (Fig. 12c), whereas far-field errors correspond to the absence of clearly visible patterns, due to the lower resolution and the lower velocities. Computed discharges deviated severely from the rating curve outputs: $-35 \%$ and $+45 \%$, respectively for image sequences (c) and (d).

As the far-field parts of the image seemed of poorer quality, the velocity data obtained beyond $80 \mathrm{~m}$, i.e., roughly the mid-section, were truncated and extrapolated according to the constant-Froude extrapolation, for all image sequences. Discharges from truncated velocity fields show slightly improved results (Tab. 2, Fig. 11): apart from 4 image sequences (bold values in Tab. 2, triangles in Fig. 11), deviations were reduced to acceptable levels: all deviations $<18 \%$, average $-5.0 \%$, standard deviation $11 \%$.

As regards the four examples shown in Fig. 12, the results for flood image sequences were slightly improved by the truncation for image sequences (a) and (b), with discharge deviations from rating curve of $-1 \%$ and $-12 \%$, respectively. The truncation also significantly improved the results for the intermediate discharge image sequence (c), with a more acceptable discharge deviation to rating curve of $-17 \%$. Hence, the central part of the velocity field seems to be correctly estimated, and the near-field zero velocities must negligibly contribute to the total discharge. By contrast, the truncation did not improve the fixed LSPIV performance for the low flow image sequence (d), which was even poorer, with a discharge deviation to rating curve of $+79 \%$. In this case, the central part of the velocity field is likely overestimated, due to wind effects: the river flow was very slow, and the downstream wind induced faster, small ripples at the free-surface which were actually detected by the LSPIV correlation algorithm.

The consequences of these results in terms of image acquisition strategy, of hydraulic assumptions for discharge computation, and of measurement quality, are drawn and discussed in the following sections.

\begin{tabular}{llll}
\hline Date & Q LSPIV & $\begin{array}{l}\text { Deviation } \\
\text { from rating } \\
\text { curve }\end{array}$ & $\begin{array}{l}\text { Deviation } \\
\text { from } \\
\text { ADCP }\end{array}$ \\
& {$\left[\mathrm{m}^{3} \mathrm{~s}^{-1}\right]$} & {$[\%]$} & {$[\%]$} \\
\hline $2007 / 11 / 2214: 15$ & 331 & +3.4 & +1.2 \\
$2007 / 11 / 2214: 45$ & 336 & -2.1 & -2.6 \\
$2007 / 11 / 2310: 20$ & 825 & +8.2 & - \\
$2007 / 11 / 2310: 40$ & 715 & -4.1 & - \\
$2007 / 11 / 23 \quad 10: 44$ & 642 & +7.2 & - \\
$2007 / 11 / 23 \quad 12: 10$ & 705 & +9.2 & - \\
$2007 / 11 / 2312: 31$ & 725 & +0.7 & - \\
\hline
\end{tabular}

Table 1: Evaluation of mobile LSPIV discharges (with velocity coefficient value $\alpha=0.90$ ). Discharge estimates and deviations from the rating curve outputs and from concurrent ADCP measurements.

\subsection{Discussion on LSPIV limitations and improvements}

\subsubsection{Image acquisition strategy}

The improvement of the fixed-LSPIV discharge estimates by truncating and extrapolating the far-field velocities confirm that the quality of the far-field parts of images was too poor to perform the LSPIV computation accurately. Consequently, the view angle should be moved further and zoomed, to describe the far-field with a higher resolution. It is possible to do so, since the current view angle encompasses useless near-field areas where overbank flow velocities were found to be negligible during the recorded floods.

Over the 4 bad image sequences for which deviations remain $>20 \%$ (cf. Fig. 11, triangles), 3 correspond to very poor image quality without visible natural tracers of the flow: reflections on a very smooth free-surface (2008/10/23, 2008/10/28, see Fig. 12d), bed rocks visible through the clear water (2008/10/28, see Fig. 12d), fuzzy images due to focus drift (2008/11/05). Criteria for discarding poor quality image pairs should be sought to improve the robustness of the discharge measurements. Conditions with smooth free-surface and clear water only occur for low-flow periods when LSPIV measurements are not intended, and when image sequences could be discarded. 


\begin{tabular}{|c|c|c|c|c|}
\hline Date & Q LSPIV & $\begin{array}{l}\text { Deviation } \\
\text { from } \\
\text { rating } \\
\text { curve } \\
{[\%]}\end{array}$ & $\begin{array}{l}\text { Q } \\
\text { LSPIV } \\
(80 \mathrm{~m})\end{array}$ & $\begin{array}{l}\text { Deviation } \\
\text { from } \\
\text { rating } \\
\text { curve } \\
\text { [\%] }\end{array}$ \\
\hline $2008 / 10 / 22$ 13:00 & 1881 & -22 & 1961 & -18 \\
\hline $2008 / 10 / 22$ 16:45 & 2404 & +46 & 2422 & +47 \\
\hline 2008/10/22 17:15 & 1829 & +16 & 1841 & +17 \\
\hline 2008/10/23 09:00 & 511 & +21 & 602 & +43 \\
\hline $2008 / 10 / 23$ 17:30 & 265 & -11 & 281 & -3 \\
\hline $2008 / 10 / 28 \quad 10: 00$ & 113 & +45 & 140 & +79 \\
\hline 2008/11/01 11:00 & 359 & -8 & 364 & -7 \\
\hline 2008/11/02 12:00 & 2156 & -10 & 2373 & -1 \\
\hline 2008/11/03 08:45 & 953 & -17 & 1018 & -12 \\
\hline $2008 / 11 / 04 \quad 12: 30$ & 411 & -21 & 525 & +1 \\
\hline $2008 / 11 / 05$ 12:00 & 225 & -50 & 303 & -33 \\
\hline 2008/11/05 14:40 & 307 & -35 & 389 & -17 \\
\hline
\end{tabular}

Table 2: Evaluation of fixed LSPIV discharges (with velocity coefficient value $\alpha=0.90$ ). Discharge estimates and deviations from the rating curve outputs, with and without truncating and extrapolating velocities beyond $80 \mathrm{~m}$.

The fourth bad sequence (2008/10/22) corresponds to a highly unsteady 24-min sampling period with rapidly dropping discharge after the flood peak: $-0.42 \mathrm{~m}$ per hour, $-240 \mathrm{~m}^{3} / \mathrm{s}$ per hour (i.e., $-14 \%$ of the mean discharge), cf. Fig. 5. This shows that the strategy for image acquisition was not the best choice. Instead of sampling isolated image pairs evenly distributed in time, it would be better to acquire image series separated by a rest time interval. For instance, keeping the same amount of images to store and process as in the current implementation, 23 image pairs acquired over $2.4 \mathrm{~s}$ (12 successive images) with a rest time interval of 24 minutes could be processed. An increased number of image pairs in a short sampling time period would allow the averaging of an increased number of instantaneous LSPIV velocity fields, which would likely improve the quality of discharge estimates. Indeed, the main difference between mobile and fixed LSPIV tests lies in the number of averaged image pairs: 600 image pairs sampled over 2 min, versus 12 image pairs over 24 min.

\subsubsection{Hydraulic assumptions for discharge computation}

The simple assumption of a velocity coefficient, $\alpha$, constant both in space and time for a given cross-section is very convenient. The variability of $\alpha$ derived from the analysis of available gauging data at Sauze-St Martin was acceptable: $\sigma=0.04$ across the section, and $\sigma=0.05$ over the bulk velocity range of $0.12-2.6 \mathrm{~m} \mathrm{~s}^{-1}$. The mean values provided by both the ADCP data and current-meter data were consistent and close to $\alpha=0.90$. However, further velocity measurements would be necessary to firmly verify that the value of $\alpha$ keeps constant for high discharges $\left(Q>700 \mathrm{~m}^{3} \mathrm{~s}^{-1}\right)$, or highly unsteady events. In the case of overbank flow events, the mean value of $\alpha$ may change significantly and $\alpha$ values may vary throughout the cross-section [18]. This effect is especially marked in the case of non-prismatic compound channel geometry [21].

Because the vertical velocity distribution deviates from the log law and becomes constant in the outer part of the flow, above relative elevation $\beta=0.6$, the mean value $(\alpha=0.90)$ retained for the velocity coefficient at SauzeSt Martin is significantly different from the commonly used default value $(\alpha=0.85)$. From the similar analysis of vertical velocity profiles measured at their study site, Le Coz et al. [16] obtained a mean log-constant profile with $\alpha=0.91$ whereas Jodeau et al. [12] found a mean $\log$ profile with a lower velocity coefficient value $(\alpha=0.79)$. Indeed, $\alpha$ is site-specific and affected by local conditions which govern the local flow structure (bed roughness, width-to-depth aspect ratio, non uniform conditions, etc.). As it causes multiplicative and systematic errors on LSPIV discharge estimates, the mean value and variability of $\alpha$ should be investigated using available velocity measurements at the considered cross-section. Though it is useful to define the value of $\alpha$ with much care, it must also be considered that maximal deviations from the default value (0.85) are usually less than $10 \%$, which remains acceptable for most flood 
discharge estimates. Therefore, the interest of applying the LSPIV method at non-gauged sites is not questionable, at least for providing new data during floods.

Another critical hydraulic assumption for LSPIV discharge computation is the method used for extrapolating unmeasured or discarded velocities. The results of the LSPIV performance tests showed that it may be better to discard or truncate poor-quality velocity measurements in the far-field of the images. However, the more the extrapolatedto-measured discharge ratio increases, the more errors induced by the extrapolation method become detrimental to the quality of discharge estimates. Consequently, much attention should be paid to the extrapolation method to be implemented for a given river cross-section. In this study, a practical method [7] for the extrapolation of missing or truncated velocities was used assuming that the local Froude number in the considered subsection remain constant and equal to the local Froude number of the closest computed LSPIV node (Section 2.4.1). Further work is needed to validate experimentally or numerically the constant Froude assumption at the study site under consideration.

Generally speaking, indirect methods for measuring discharges such as the LSPIV technique can be greatly improved by the hydraulic analysis of the implementation site for assessing the flow structure over a range of hydraulic conditions. This can be achieved by the experimental investigation of available velocity measurements or by numerical simulation.

\subsubsection{Quality of LSPIV discharge measurements}

From the tests performed simultaneously with the mobile LSPIV system and a Doppler profiler (ADCP), both deployed at the same river section for a discharge of $300 \mathrm{~m}^{3} \mathrm{~s}^{-1}$, LSPIV velocities were found to fall within a $\pm 10 \%$ interval around the reference data. Unfortunately, such velocity-velocity comparison tests were not conducted for higher discharge values. The quality of LSPIV velocity measurements performed for higher flood events and consequently higher flow velocities is likely to be the same, because the time interval between images in a pair, $\Delta t$, can be reduced as low as $40 \mathrm{~ms}$. However, the quality of fixed LSPIV velocity measurements was obviously poorer, especially in the far field, due to poorer image quality and insufficient averaging of random errors.

The reported tests give an idea of the accuracy that can be expected for flash-flood discharges measured by both considered LSPIV systems. For the mobile LSPIV system, observed deviations from the rating curve outputs were $<10 \%$ (mean $\mu=+3 \%$, standard deviation $\sigma=5 \%$ ). For the fixed LSPIV system, most of the tested sets of image pairs yielded deviations $<18 \%(\mu=-5 \%, \sigma=11 \%)$. Detrimental image conditions or flow unsteadiness during the image sampling period led to large deviations ranging $30-80 \%$. Therefore, in good conditions of operation, a $20 \%$ accuracy level is a realistic objective for LSPIV flood discharge measurements, provided some technical improvements are made. Such remote discharge estimates constitute very valuable data for the establishment of high-discharge parts of rating curves and the monitoring of flash-floods at gauged as well as non-gauged stations.

Though these tests results are encouraging, further tests as well as a thorough uncertainty analysis are still required for determining the quality of LSPIV discharge measurements. A comprehensive set of the main sources of error should be investigated, including image quality, orthorectification (water level, camera movements...), surface velocity errors (wind effects, tracer quality, low correlation), hydraulic unsteadiness and image sampling and data averaging protocol, complex flow structure (variability of the velocity coefficient, extrapolation methods for unmeasured areas). In addition to field validation tests, numerical simulation tools are valuable for assessing the LSPIV uncertainties [10].

\section{Conclusions and perspectives}

Validation tests using both mobile and fixed LSPIV systems were conducted at the Sauze-Saint-Martin gauging station, for discharges ranging from 300 to $2500 \mathrm{~m}^{3} \mathrm{~s}^{-1}$, i.e., for mean velocities ranging from $1.0 \mathrm{~m} \mathrm{~s}^{-1}$ to $2.9 \mathrm{~m} \mathrm{~s}^{-1}$. A mean velocity coefficient value of $\alpha=0.90$ (standard deviation $\sigma=0.05$ ) was derived from available measurements by conventional methods. For $300 \mathrm{~m}^{3} \mathrm{~s}^{-1}$, LSPIV velocities throughout the river cross-section were found to be in good agreement $( \pm 10 \%)$ with concurrent measurements by Doppler profiler (ADCP). Mobile and fixed LSPIV discharges usually were in acceptable agreement $(<20 \%)$ with the rating curve, though some problems still have to be solved for validating continuous measurements with the fixed LSPIV system. The sources of errors that likely explain the poorer results of the fixed LSPIV tests are: some image sequences with poor quality, due to external conditions or instrumental limitations; insufficient number of averaged image pairs; averaging time period too long 
compared with discharge variations; velocity coefficient variability with flow conditions; uncertainty associated with the constant-Froude extrapolation of missing or truncated velocities.

The present study case on a Mediterranean river during natural floods shows that LSPIV application is possible without adding tracers to improve the assessment of flash-flood discharges. Main perspectives for improving the measuring system consist of changing the image sampling strategy (series instead of isolated pairs) and defining criteria for discarding improper image pairs. Also, improvements of the LSPIV algorithm or alternative image analysis technique such as the Space Time Image Velocimetry technique developped by Fujita et al. [6] should be implemented and tested. Since a robust real-time discharge computation is intended, the relevance of hydraulic assumptions has to be confirmed by the investigation of the flow structure using ADCP velocity measurements and 1D/2D hydraulic modelling. In addition to further field validation tests, uncertainty analysis and sensitivity analysis using numerical simulation would be of practical interest. That the velocity coefficient is site-specific shows that measuring surface velocities and assessing their uncertainty is not sufficient for estimating the accuracy of the LSPIV discharge measurements. The paper provides methods for assessing the mean value and variability of the velocity coefficient from available informations (velocity profile measurements, bed roughness, water depth, etc.).

Even if further study of the accuracy of the LSPIV flood discharge measurements is required, the technique is confirmed to be a highly valuable hydrological tool for both gauged and non-gauged stream sections. The LSPIV method can be used for providing velocity and discharge data during fast floods when conventional techniques fail or are very difficult to deploy. The extension of the LSPIV station network throughout the Ardèche river catchment is planned for coming years. The flood discharge measurements provided by LSPIV stations will be most useful for the critical analysis of rating curves and their extrapolated parts. Mobile LSPIV measurements at ungauged sites during floods should be also conducted. The improvement of flood discharge monitoring will increase our knowledge of hydro-meteorological processes associated to Mediterranean flash-floods.

\section{Acknowledgements}

This research task was supported by CNR (Compagnie Nationale du Rhône), Cemagref, OHMCV (CévennesVivarais Mediterranean Hydrometeorological Observatory), Région Rhône-Alpes. The operators who produced all the data and information used in this study are gratefully acknowledged, especially Serge Françon, Nicolas Janin, Jérôme Laurent, Xavier Martin, Thierry Pantel (CNR), Nathalie Ball, Mickaël Lagouy, Fabien Thollet (Cemagref).

\section{References}

[1] Cardoso, A., Graf, W., Gust, G., 1989. Uniform flow in a smooth open channel. Journal of Hydraulic Research 27 (5), $603-616$.

[2] Costa, J., Cheng, R., Haeni, F., Melcher, N., Spicer, K., Hayes, E., Plant, W., Hayes, K., Teague, C., Barrick, D., 2006. Use of radars to monitor stream discharge by noncontact methods. Water Resources Research 42 (7), 14 p.

[3] Creutin, J. D., Muste, M., Bradley, A. A., Kim, S. C., Kruger, A., 2003. River gauging using PIV techniques: a proof of concept experiment on the Iowa river. Journal of Hydrology 277, 182-194.

[4] Delrieu, G., Ducrocq, V., Gaume, E., Nicol, J., Payrastre, O., Yates, E., Kirstetter, P. E., Andrieu, H., Ayral, P. A., Bouvier, C., Creutin, J. D., Livet, M., Anquetin, S., Lang, M., Neppel, L., Obled, C., du Chatelet, J. P., Saulnier, G. M., Walpersdorf, A., Wobrock., W., 2005. The catastrophic flash-flood event of 8-9 september 2002 in the Gard region, France: a first case study for the Cévennes-Vivarais Mediterranean Hydro-meteorological Observatory. Journal of Hydrometeorology 6, 34-52.

[5] Fujita, I., Muste, M., Kruger, A., 1998. Large-scale particle image velocimetry for flow analysis in hydraulic engineering applications. Journal of Hydraulic Research 36 (3), 397-414.

[6] Fujita, I., Watanabe, H., Tsubaki, R., 2007. Development of a non-intrusive and efficient flow monitoring technique: The space time image velocimetry (STIV). International Journal of River Basin Management, 5 (2), 105-114.

[7] Fulford, J., Sauer, V., 1986. Comparison of velocity interpolation methods for computing open-channel discharge. U.S. Geological Survey Water-supply Paper 2290, 139-144.

[8] Gaume, E., Bain, V., Bernardara, P., Newinger, O., Barbuc, M., Bateman, A., Blaskovicová, L., Blöschl, G., Borga, M., Dumitrescu, A., Daliakopoulos, I., Garcia, J., Irimescu, A., Kohnova, S., Koutroulis, A., Marchi, L., Matreata, S., Medina, V., Preciso, E., Sempere-Torres, D., Stancalie, G., Szolgay, J., Tsanis, I., Velasco, D., Viglione, A., 2009. A compilation of data on European flash floods. Journal of Hydrology, 367 (1-2), 70-78.

[9] Hauet, A., Kruger, A., Krajewski, W. F., Bradley, A., Muste, M., Creutin, J. D., 2008. Experimental system for real-time discharge estimation using an image-based method. Journal of Hydrological Engineering 13 (2), 105-110.

[10] Hauet, A., Creutin, J.-D., Belleudy, P., 2008. Sensitivity study of large-scale particle image velocimetry measurement of river discharge using numerical simulation. Journal of Hydrology 349 (1-2), 178-190.

[11] IRS, 2000. Etude globale pour une stratégie de réduction des risques dus aux crues du Rhône (Global study for a strategy for reducing risks due to the floods of the Rhône river). Tech. Rep. 1st part, Institution interdépartementale des bassins Rhône-Saône (IRS). 
[12] Jodeau, M., Hauet, A., Paquier, A., Le Coz, J., Dramais, G., 2008. Application and evaluation of LS-PIV technique for the monitoring of river surface velocities in high flow conditions. Flow Measurement and Instrumentation 19(2), 117-127.

[13] Kim, Y., Muste, M., Hauet, A., Krajewski, W. F., Kruger, A., Bradley, A., 2008. Stream discharge using mobile large-scale particle image velocimetry: A proof of concept. Water Resources Research 44, W09502.

[14] Lang, M., Naulet, R., Recking, A., Cœur, D., Gigon, C. 2002. Etude de cas: L'analyse des pluies et crues extrêmes observées depuis 200 ans dans un bassin cévenol, l'Ardèche (A case study on the Ardèche river: Flood frequency analysis of historical events within the two last centuries, in French). La Houille Blanche, 6-7, 131-138.

[15] Lang, M., Pobanz, K., Renard, B., Renouf, E., Sauquet, E., 2009. Do monsters stand up to rating curves scrutiny? Submitted for publication in Hydrological Sciences Journal.

[16] Le Coz, J., Pierrefeu, G., Jodeau, M., Paquier, A., 2007. Mean vertical velocity profiles from aDcp river discharge measurement datasets. In: 32nd Congress of IAHR. Venice, Italy.

[17] Le Coz, J., Pierrefeu, G., Paquier, A., 2008. Evaluation of river discharges monitored by a fixed side-looking Doppler profiler (H-aDcp). Water Resources Research 44, W00D09, doi:10.1029/2008WR006967.

[18] Marjang, N., Merkley, G. P., 2009. Surface velocity coefficients for application of the float method in rectangular and compound open channels. Irrigation Science, 27(6), 457-470.

[19] Muste, M., Fujita, I., Hauet, A., 2008. Large-scale particle image velocimetry for measurements in riverine environments. Water Resources Research, 44, W00D19, doi:10.1029/2008WR006950.

[20] Olivier, A., Blanquart, B., Pierrefeu, G., Scotti, M., 2008. Incertitude sur les débits calculés à partir de courbes de transformation hauteur/débit (uncertainty associated to discharges computed from stage/discharge curves). In: SHF conference on Hydrological measurements and uncertainties, 1-2 April, 2008, Paris, France.

[21] Proust, S., Bousmar, D., Rivière, N., Paquier, A., Zech, Y., 2009. Non-uniform flow in compound channel: a 1D-method for assessing water level and discharge distribution. Water Resources Research, 45, W12411, doi:10.1029/2009WR008202.

[22] Rantz, S. E., 1982. Measurement and computation of streamflow. Vol. 1, Measurement of stage and discharge, Water-Supply Paper 2175. U. S. Geological Survey, Washington.

[23] Schmidt, A., 2002. Analysis of stage-discharge relations for open-channel flows and their associated uncertainties. Ph.D. thesis, University of Illinois, Urbana-Champaign.

[24] Smart, G.M., 1999. Turbulent veloicty profiles and boundary shear in gravel bed rivers. Journal of Hydraulic Engeering, 125(2), 106-116.

[25] Wilcock, P.R., 1996. Estimating local bed shear stress from velocity observations. Water Resources Research, 32(11), 3361-3366. 


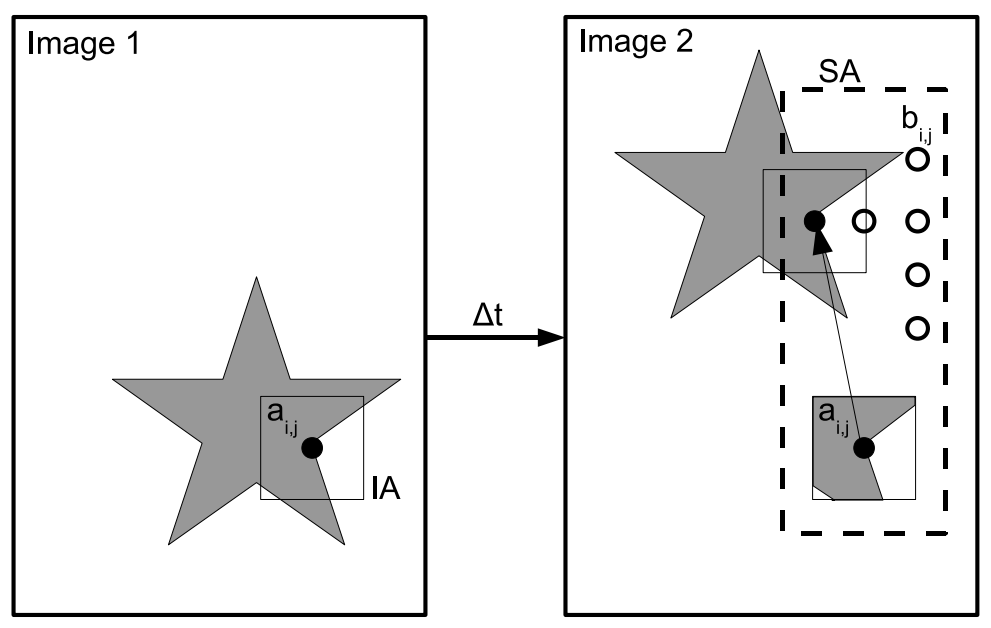

Figure 1: Principles of the cross-correlation LSPIV analysis. A flow tracing pattern is represented by a star in two consecutive images separated by time interval $\Delta t$. The interrogation area (IA) centred at point $a_{i, j}$ in image 1 is tracked in image 2 at points $b_{i, j}$ within the search area (SA, dashed rectangle).



Figure 2: Aerial view (Google Earth) of the Ardèche river at Sauze-St Martin. 


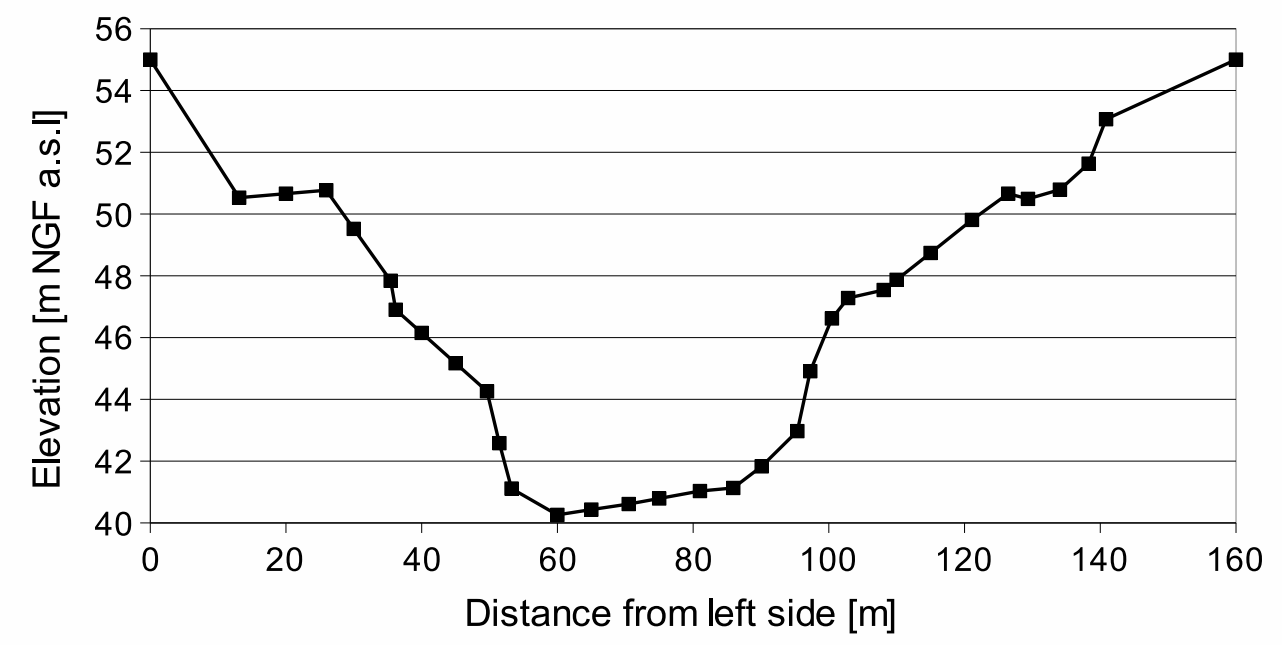

Figure 3: Cross-sectional profile used for LSPIV discharge computation, in metres above sea level (reference elevation system: NGF IGN69).

a)

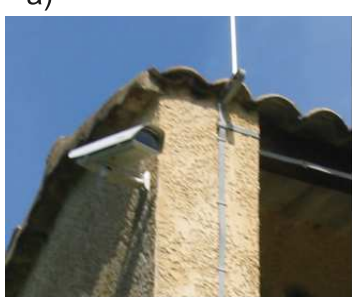

c) b)
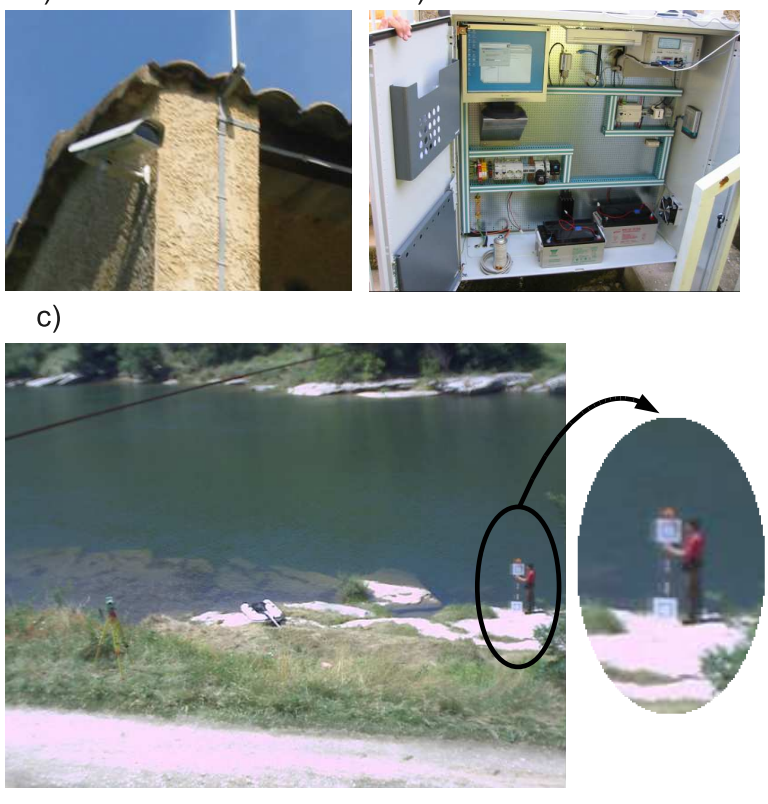

d)

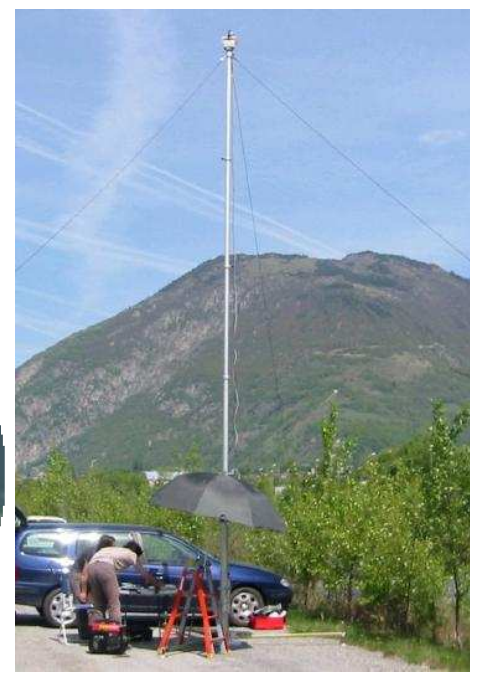

Figure 4: Fixed and mobile LSPIV measuring systems. Digital camera (a) and fixed LSPIV station (b) installed at the Sauze-St Martin gauging station. Recorded image including an operator with two targets for georeferencing two Ground Reference Points (c). Mobile LSPIV system (d) used in this study and comprising a telescopic mast supporting a remotely-controlled camera platform. 




Figure 5: Hydraulic conditions during the LSPIV validation tests in 2007 and 2008: instant discharge time series recorded at the Sauze-St Martin gauging station (gray line, CNR), LSPIV campaign time locations (circles).

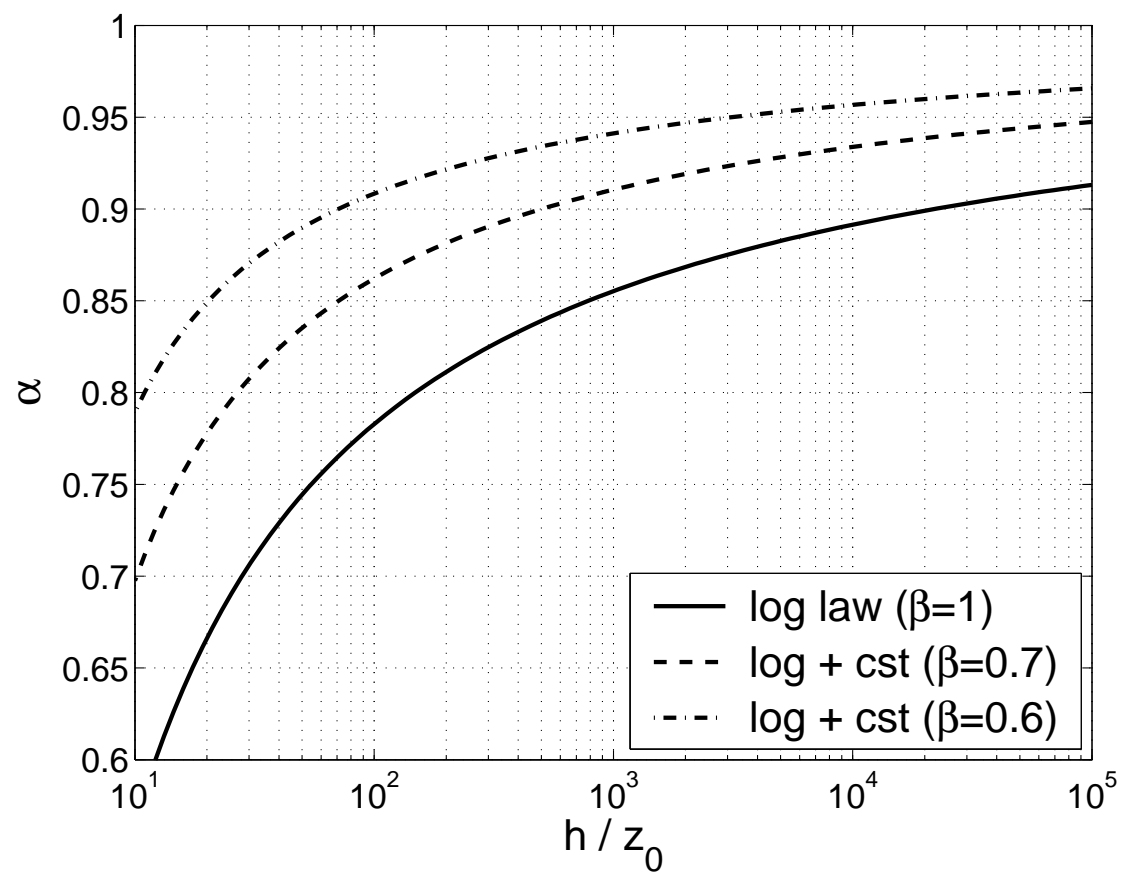

Figure 6: Variation of the velocity coefficient, $\alpha$, with the roughness length to flow depth ratio, $z_{0} / h$, assuming a theoretical vertical velocity distribution: logarithmic profile over the whole flow depth, or logarithmic profile and constant profile below and above relative elevation $\beta$, respectively. 




Figure 7: Non-dimensional velocity profiles measured at Sauze-St Martin using a $600 \mathrm{kHz}$ ADCP for a discharge of $300 \mathrm{~m}^{3} \mathrm{~s}^{-1}$. The mean flow structure is modelled by a logarithmic profile and a constant profile below and above relative elevation $\beta=0.6$, respectively. The resulting mean velocity coefficient is $\alpha=0.90$ with standard deviation 0.04 . 


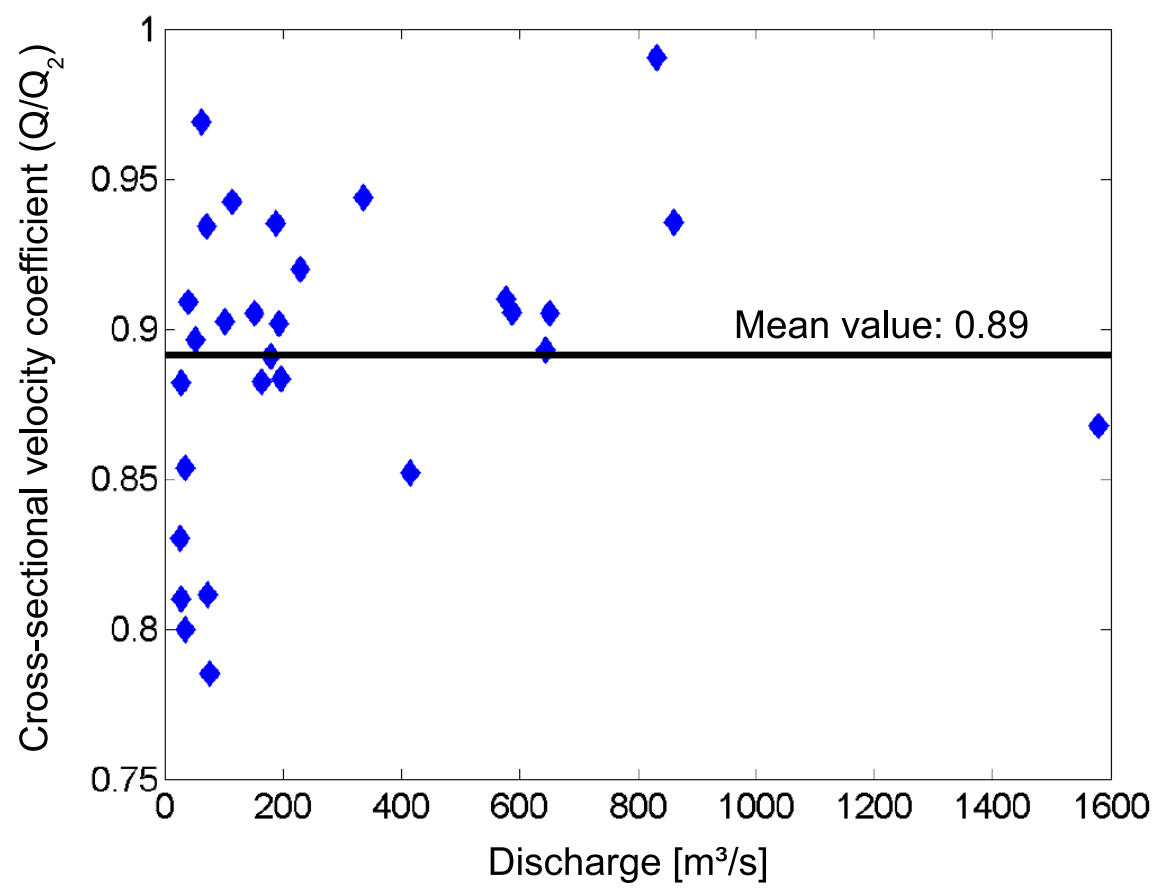

Figure 8: Cross-section averaged velocity coefficients derived from conventional current-meter gaugings conducted by CNR at Sauze-St Martin. $Q$ is the gauged discharge and $Q_{2}$ is the discharge computed with near-surface velocities $(20 \mathrm{~cm})$ instead of depth-averaged velocities. The mean cross-sectional velocity coefficient value is $Q / Q_{2}=0.89$ with standard deviation 0.05 . 




Figure 9: Surface velocity field measured by LSPIV during mobile tests conducted on November 11, 2007 at Sauze-St Martin. Right (RB) and left (LB) banks are indicated by dashed lines.



Figure 10: Validation of LSPIV velocity measurements from mobile tests conducted on November 11, 2007 at Sauze-St Martin. Comparison of corrected LSPIV velocities (solid blue line, $\alpha=0.90$ ) with ADCP depth-averaged velocities (red dashed line, with $\pm 10 \%$ interval, black dotted line). 


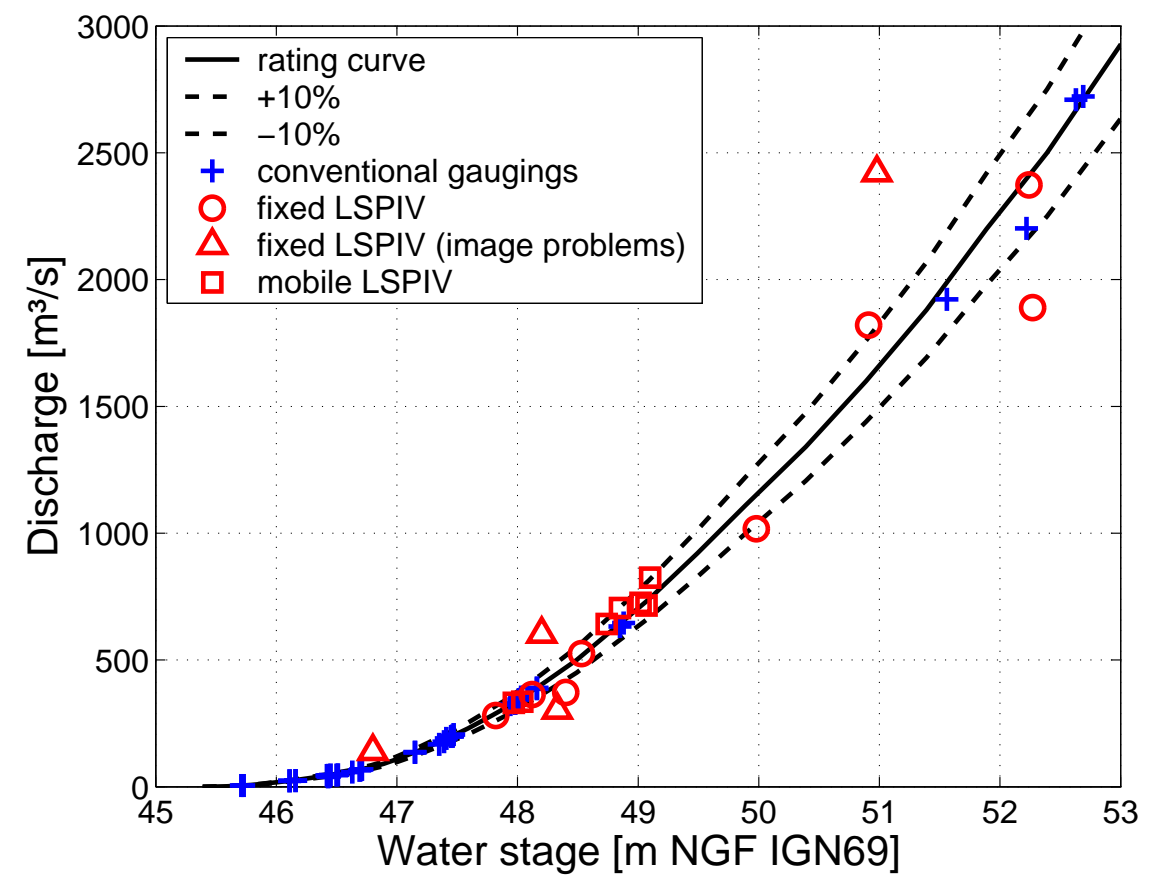

Figure 11: Validation of LSPIV discharge measurements from mobile and fixed tests conducted in 2007 and 2008 at Sauze-St Martin (velocity coefficient $\alpha=0.90$ ). Comparison of LSPIV discharge measurements (squares: mobile, circles: fixed, triangles: fixed affected by image problems) with the rating curve (solid line, with dashed lines: $\pm 10 \%$ interval, crosses: conventional gaugings). The conventional gaugings were conducted using either a currentmeter from the cableway, either a vessel-mounted ADCP. For fixed LSPIV tests, velocities were truncated and extrapolated beyond $80 \mathrm{~m}$. 

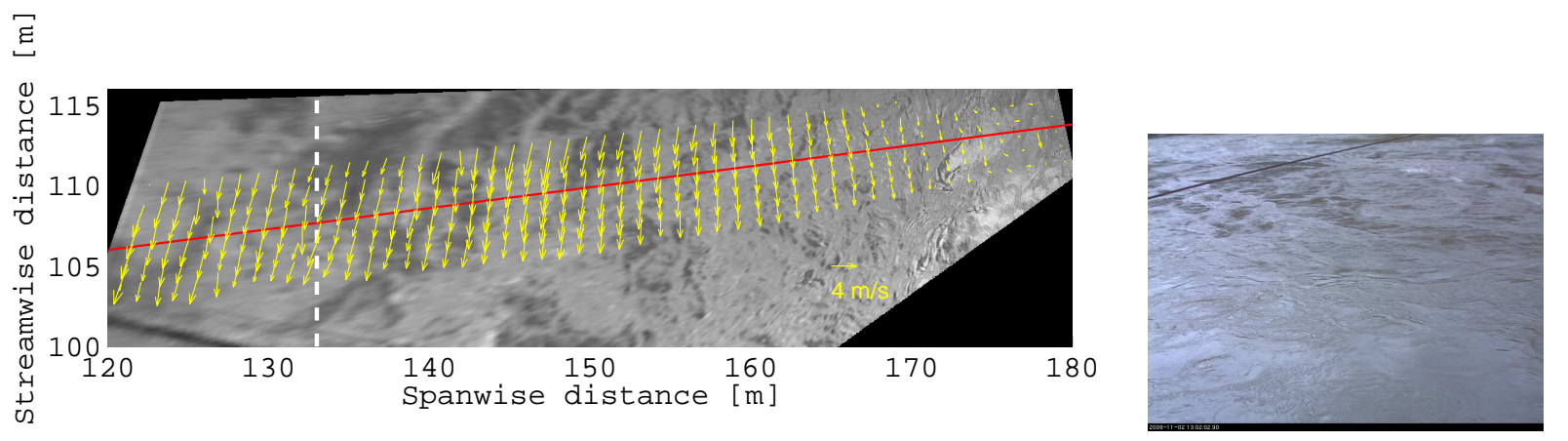

(a)
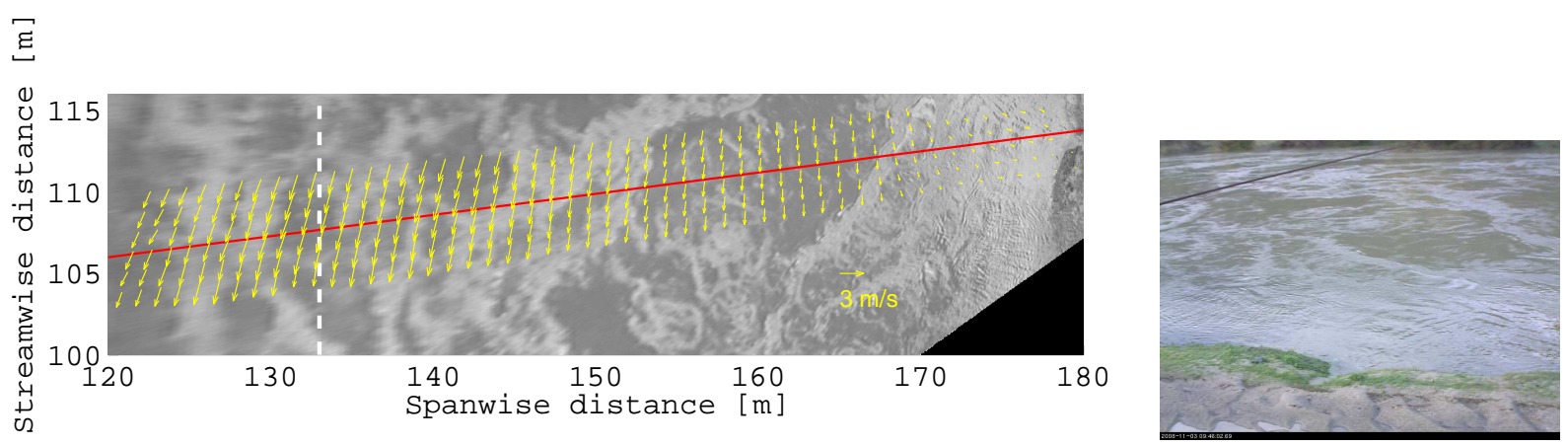

(b)

छ
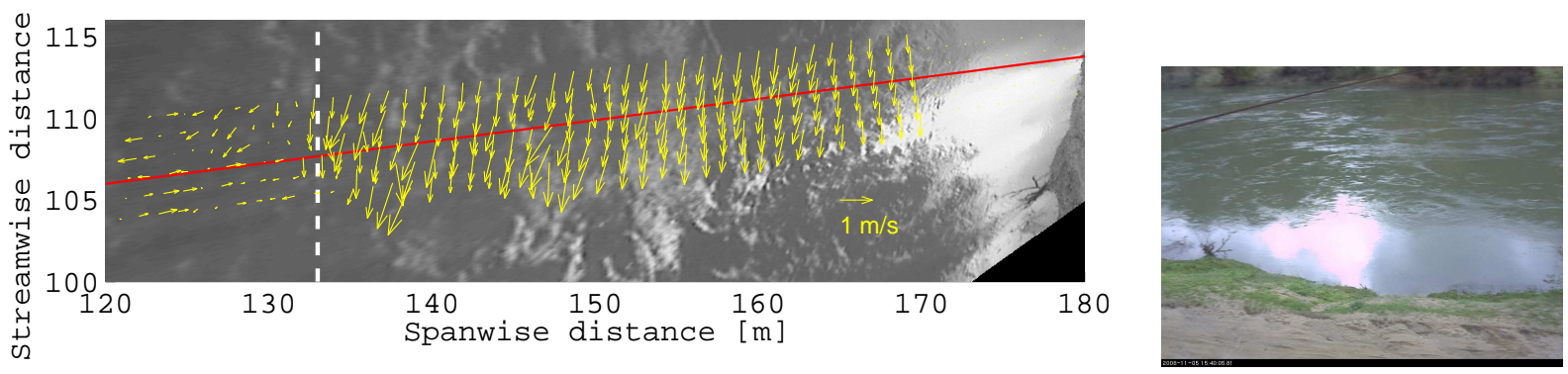

(c)

㤩


(d)

Figure 12: Typical results of the fixed LSPIV performance tests: image sequences of 2008/11/02 12:00 (a), 2008/11/03 08:45 (b), 2008/11/05 14:40 (c), 2008/10/28 10:00 (d). Left column: LSPIV velocity fields on grayscale ortho-rectified image, with the gauging transect (red solid line) and the $80 \mathrm{~m}$ range beyond which velocities are truncated and extrapolated (white dashed line). Right column: corresponding raw images as yielded by the camera. 